\title{
Das urnas às ruas: uma análise comparada das políticas econômicas dos governos João Goulart e José Sarney sob a ótica da reputação política
}

\section{Ivan Colangelo Salomão' Rafael Moraes ${ }^{2}$}

\begin{abstract}
Resumo: Diante da similitude conjuntural em que os vice-presidentes João Goulart e José Sarney assumiram o poder, este trabalho tem por objetivo analisar a razão das divergências nas políticas econômicas adotadas nos respectivos momentos históricos. Advoga-se a hipótese de que a busca pela legitimidade de que ambos careciam foi instrumentalizada através de políticas antagônicas em função das disparidades das biografias políticas ostentadas por cada um dos políticos. A reputação política de Goulart não lhe permitia a adoção de medidas heterodoxas tais quais as levadas a cabo por Sarney para angariar o apoio popular que não obteve pelas urnas.
\end{abstract}

Palavras-chave: João Goulart - José Sarney - Reputação política - Legitimidade

Classificação JEL: N16.

From the urns to the streets: a comparative analysis of the economic policies of João Goulart and José Sarney's administrations from the political reputation perspective

\begin{abstract}
Face to the similarities that both the vice-presidents João Goulart and José Sarney faced when assumed the Brazilian government, this article has the purpose to analyze the reason of the differences verified in the economic policies implemented by those politicians in their respective governments. Considering the absence of political legitimacy faced by both of them, the antagonism verified in their economic policies could find themselves a reason based on the disparities verified in their political biography. The Goulart's political reputation prevented him of the adoption of the heterodox economic measures implemented by Sarney and which had given him the popular support that was firstly denied to him.
\end{abstract}

Keywords: João Goulart - José Sarney - Political reputation - Legitimacy

1 Professor Adjunto da Faculdade de Ciências Econômicas e do Programa de Pós-Graduação em Economia da Universidade Federal do Rio Grande do Sul (PPGE/UFRGS). E-mail: ivansalomao@ gmail.com.

2 Mestre em Economia pela Universidade Federal do Rio Grande do Sul e doutorando em Desenvolvimento Econômico pela Universidade Estadual de Campinas. E-mail: moraes. economia@yahoo.com.br. 


\section{Introdução}

Não são raros os episódios, ao longo da história republicana brasileira, em que o presidente da República, impedido por qualquer motivo de manter-se no cargo, teve que ser substituído pelo vice-presidente. Golpes de Estado, interdições legais, prostração ou falecimento foram algumas das causas de alheamento de diversos chefes de Estado brasileiros. Em comum, o corolário inevitável à maioria dos casos: a ausência de legitimidade que se tornou uma realidade constante nos mandatos de alguns dos vices que vieram a assumir o governo.

$\mathrm{O}$ fato de terem sido eleitos como vice-presidentes em suas respectivas chapas contribui para explicar tal fenômeno. Dentre todos os casos ocorridos, dois episódios merecem destaque: a posse de João Goulart3, em 7 de setembro de 1961, vindo a ocupar a vaga do presidente renunciante Jânio Quadros, e a ascensão de José Sarney, em 15 de março de 1985, que assumiu o cargo após o presidente indiretamente eleito, Tancredo Neves, ter sido internado em grave estado de saúde, situação da qual não viria a se recuperar.

João Goulart, empossado após sete conturbados meses do governo Jânio Quadros - cuja renúncia inesperada reforçou a crise política que culminaria no golpe de 1964 -, havia sido eleito vice-presidente em um período em que os pleitos para presidente e vice eram realizados separadamente. Em plena vigência da Guerra Fria, o político com histórico relacionado às causas populares e progressistas angariou a antipatia do establishment nacional e estrangeiro. Nos quase três anos de seu governo - somados os períodos parlamentarista e presidencialista -, conviveu com oposição ferrenha de setores importantes da sociedade brasileira, principalmente da mídia, de setores militares e de parte das elites econômicas que buscaram desestabilizá-lo.

José Sarney, parlamentar de tradição conservadora, edificou sua carreira política sob as hostes do regime militar. Compôs a chapa de Tancredo Neves no Colégio Eleitoral devido, justamente, à sua ligação com o governo discricionário que defendeu desde o início. Egresso do mais antigo estrato político do país, representante do governo rechaçado pelas ruas e benemerente às causas da elite dominante, Sarney assumiu a Presidência da República em meio à comoção nacional causada pela enfermidade de Tancredo. A frustração do anseio popular diante do abalo causado pela doença de Tancredo, sua conhecida identificação com a ditadura militar e as dificuldades em conter a grave crise econômica pela qual passava o país, foram os principais componentes da crise de legitimidade contra a qual Sarney lutou durante quase todos os cinco anos de seu mandato.

3 João Goulart foi eleito vice-presidente, em 1960, com 36,1\% dos votos, cerca de 300 mil votos a mais que seu principal concorrente, Milton Campos, da União Democrática Nacional. Nessa mesma eleição, na qual presidente e vice eram votados separadamente, foi eleito o presidente Jânio Quadros, da chapa da UDN, com 48,3\% dos votos (FERREIRA, 2011). 
As similaridades observadas entre esses dois casos não se resumem ao fato de terem sido vice-presidentes com dificuldades de legitimação. Ambos os governantes assumiram o comando do país em meio a adversidades que marcavam o esgotamento de períodos de bonança econômica. A crise iniciada em 1961, que se seguia ao sucesso do Plano de Metas (1955-1960), caracterizou-se pela redução do crescimento do Produto, aumento da inflação e grandes déficits orçamentário e do balanço de pagamentos. Já em 1985, o país enfrentava conjuntura bastante similar. Após o sucesso do "milagre econômico" (1968-1973) e o relativo êxito do II PND (1975-1979), o país assistia novamente ao recrudescimento da inflação, à queda nos índices de crescimento econômico e ao aumento dos déficits público e externo.

A despeito das semelhanças eloquentes, as políticas econômicas adotadas por esses dois governos foram significativamente diferentes, quando não opostas, em diversos aspectos. O presidente Goulart iniciou seu mandato patrocinando políticas de caráter ortodoxo voltadas à estabilização inflacionária. Ao longo de seu governo, entretanto, abandonou paulatinamente a parcimônia e empenhou ações cada vez mais socializantes, mais próximas aos setores da dita "esquerda radical".

Por seu turno, o presidente Sarney, diante de dificuldades assemelhadas, seguiu um caminho inverso. Antes de completar seu primeiro ano no governo, patrocinou o lançamento de um plano de estabilização com elementos reconhecidamente heterodoxos, o qual culminaria com a decretação da moratória da dívida externa, em 1987. No decorrer dos anos, entretanto, o presidente alterou claramente o perfil das políticas implementadas, finalizando seu governo com medidas liberalizantes e com planos convencionais de combate à inflação e ao déficit público.

O presente trabalho tem por objetivo analisar as razões das políticas econômicas dos dois presidentes, por meio de uma abordagem que vai além da busca de racionalidade meramente econômica. Nesse ponto, advogar-se-á a hipótese de que, guardadas as diferenças históricas, o comportamento inverso observado no perfil de suas políticas econômicas está relacionado também a aspectos políticos, mormente a busca de legitimidade frente ao vácuo de poder deixado pela ausência do presidente. Nesse sentido, ainda que o cargo de vice-presidente lhes garantisse a autoridade legal, considera-se que ambos os governantes intentaram, por meio da política econômica, granjear credibilidade junto a determinados segmentos sociais, sobre os quais erigiram suas próprias trajetórias políticas.

Subjaz a nossa hipótese a ideia de que a construção das políticas econômicas ocorre em meio a uma interposição de "poderes", no qual a posição do chefe do Executivo é apenas uma das partes (WEBER, 2000). Dessa forma, as distintas políticas em tela vão de encontro àquelas que se esperaria diante da biografia de cada presidente, fato que pode representar simultaneamente a busca por ampliação da base de sustentação, bem como a incapacidade política de impor qualquer outra ordem de fatores dado o quadro de forças. No fundo, expõe-se a percepção de que o poder discricionário do Estado e, especificamente, do Executivo é menos absoluto do que se supõe. Em outros termos, o Estado não é tido como sujeito absoluto, 
fonte de seu próprio poder, mas fruto da materialização de uma estrutura social concretizada na disputa de espaço dentro de suas estruturas. É nesse sentido que se pretende demonstrar que a maior ou menor autonomia do governante frente às forças sociais que lhe envolvem advém da legitimidade que logra auferir diante delas.

Diante desse cenário, para concretizar os objetivos expostos, estruturou-se o presente trabalho em quatro pontos, incluindo essa breve introdução. $\mathrm{Na}$ segunda parte, analisar-se-á a figura do presidente João Goulart e a política econômica de seu governo. Em seguida, discorrer-se-á acerca da biografia de José Sarney e das medidas econômicas durante seu mandato. No quarto ponto, serão analisados os motivos que levaram às diferentes estratégias, seguido, por fim, das considerações finais.

\section{0 governo João Goulart}

\subsection{João Goulart: biografia política}

João Belchior Marques Goulart, ou Jango como era popularmente conhecido, ostentou uma carreira política ao mesmo tempo polêmica e meteórica. Grande pecuarista do interior do Rio Grande do Sul, Goulart possuía pouco contato com os meios políticos até meados dos anos 1940, salvo o fato de ter nascido e residido em São Borja, cidade natal de Getúlio Vargas.

O afastamento de Vargas da Presidência da República, em 1945, e sua retirada para São Borja fizeram com que o ex-mandatário se aproximasse de Goulart. Não tardou até Jango ingressar na política ao eleger-se deputado estadual em 1947. De presidente do Diretório Municipal do Partido Trabalhista Brasileiro de São Borja, no final dos anos 1940, Goulart chegou à presidência nacional do PTB em 1952. Nesse mesmo ano, foi eleito deputado federal, função da qual se licenciou para exercer o cargo de Secretário de Interior e Justiça do governo gaúcho (FERREIRA, 2011).

Se a carreira política de Goulart foi meteórica, também o foi a construção de sua imagem como político de grande liderança e carisma junto às classes trabalhadoras. Devido a essa habilidade com que exercia sua liderança e influência sobre os trabalhadores, Vargas o nomeou para o Ministério do Trabalho, justamente em um momento conturbado de sua segunda passagem pela presidência do país.

Em 1953, já na segunda metade de seu governo, Vargas sofria resistência de alguns setores sindicais, descontentes com os sucessivos reajustes no custo de vida. O presidente que havia implementado nos primeiros anos de seu mandato políticas anti-inflacionárias, promoveu, em 1953, uma reforma ministerial, que marcou uma guinada de seu governo para o "trabalhismo". No caso do Ministério do Trabalho, a nomeação de Goulart pretendia retomar o controle das organizações trabalhistas, que começavam a se libertar da estrutura corporativa defendida por Vargas. Corrobora essa interpretação a série de greves, à revelia dos dirigentes sindicais ligados ao governo, tidos como "pelegos", observadas no período. Tratava-se das chamadas greves independentes (FONSECA, 1989). 
Goulart assumiu a pasta do Trabalho, estabelecendo negociações com os sindicalistas, atendendo a parte de suas reivindicações e pondo fim à maioria das greves que ocorriam naquele momento. Com esse episódio, Jango consolidou sua aproximação com os setores sindicais buscando aproximá-los da estrutura do Estado. Sua política no Ministério foi caracterizada pela tentativa de antecipar-se às demandas dos trabalhadores, tratando de atendê-las antes da conflagração de conflitos. Por esse motivo é que o ministro passou a ser tido, por setores conservadores, como um incentivador da luta de classes. João Goulart foi constantemente acusado pela imprensa conservadora e por setores da UDN de pretender, junto com Vargas, instalar uma "República Sindicalista" no Brasil (BANDEIRA, 1978; FONSECA, 1989).

$\mathrm{O}$ acontecimento que encerraria sua curta passagem de oito meses pelo Ministério do Trabalho demonstra a incompatibilidade de Goulart com setores importantes da vida política nacional. Diante do recrudescimento da inflação, que corroía o poder de compra do salário-mínimo estipulado pelo governo, Goulart buscou antecipar a radicalização dos movimentos sindicais, propondo um aumento de $100 \%$ de seu valor nominal. A proposta foi veementemente rechaçada pela oposição e até por parte da equipe econômica do governo.

A reação de maior destaque veio, contudo, dos militares, através do "Manifesto dos Coronéis", documento que atacava fortemente a proposta de Goulart. Para os mais de 80 militares que subscreveram o manifesto, o reajuste do salário mínimo, tal qual solicitado por Goulart, promoveria um desajuste na relação dos salários e permitiria que um "trabalhador não qualificado" tivesse direito a um rendimento equivalente a alguém com "formação universitária" (FONSECA, 1989). Em meio à polêmica, Goulart foi afastado do ministério. Meses depois, no entanto, Vargas decretou o reajuste de $100 \%$ no salário-mínimo, gesto que teria contribuído para a conflagração do quadro que levou ao trágico fim de seu governo, em agosto de $1954^{4}$.

Durante sua passagem pelo ministério, Goulart encampou várias bandeiras que lhe renderam diversos adversários políticos. Dentre elas, destaca-se a defesa da extensão das leis sociais aos trabalhadores do campo, enfrentando os interesses das oligarquias rurais, representadas politicamente pelo Partido Social Democrático (PSD).

Com a morte de Vargas, Goulart tornou-se o seu principal herdeiro político não apenas nas fileiras do PTB, mas também no próprio "trabalhismo", síntese de um movimento que agrupava grande parte dos setores populares e que, por esse motivo, tornou-se crucial na eleição dos novos governantes do país. Foi devido à essa nova realidade que Juscelino Kubitschek, ao lançar-se candidato à Presidência da República, manteve a aliança partidária que elegeu Getúlio Vargas em 1950, tendo sido João Goulart apresentado como o seu candidato à vice da chapa PSD-PTB. O lançamento do nome de Goulart, porém, sofreu resistências, principalmente por parte do empresariado, da oligarquia rural e de parte das Forças Armadas. A aversão

4 Sobre a o auge e crise do governo de Getúlio Vargas, ver Bastos (2012). 
a Goulart refletia a antipatia com que esses setores viam a estrutura sindical a ele ligada e jungida ao PTB (BANDEIRA, 1978).

Diante da legislação eleitoral que previa a votação em separado para presidente e vice, Goulart foi eleito para seu cargo com uma votação superior à de Juscelino. Durante o governo JK (1956-1961), Goulart consolidou seu papel de liderança máxima entre as classes trabalhadoras, principalmente após 1958, quando a população passou a sentir os efeitos do aumento da inflação e da má distribuição dos frutos do desenvolvimento econômico. Goulart passou a posicionar-se com mais veemência em favor das causas trabalhistas, muitas vezes contrariando a posição oficial do governo. Foi o que ocorreu durante a deflagração das greves, momento em que Jango colocava-se ao lado dos trabalhadores ao defender o atendimento a seus pleitos. Nesse contexto de paralisações e ocupações de terras, Goulart encampou o discurso da necessidade de reformas estruturais no país, dentre elas a reforma agrária (BANDEIRA, 1978).

Com a força que havia adquirido durante seu primeiro mandato em 1956-60, Jango foi novamente escolhido candidato à Vice-Presidência pela coligação PSDPTB para as eleições de 1960. A chapa encabeçada pelo militar Henrique Teixeira Lott foi parcialmente derrotada, elegendo-se apenas Goulart, enquanto o presidente eleito foi Jânio Quadros, apoiado pela UDN.

O conturbado governo Quadros foi rapidamente interrompido pela renúncia do presidente sete meses após a sua posse, abrindo a possibilidade constitucional de o país ser governado durante os três anos finais de mandato por seu vice-presidente eleito. Antes mesmo de completar 15 anos de seu ingresso na política, Goulart tinha a oportunidade de assumir o mais alto cargo público da nação. Sem embargo, além de vertiginosa, sua carreira política também foi marcada por forte rejeição de setores mais conservadores, o que redundou num movimento de rejeição à sua posse. Nesse sentido, sua vida pública, construída em sintonia com as reivindicações das classes trabalhadoras, acabou por figurar-se como grande um empecilho à formatação de seu próprio governo.

\subsection{A política econômica do governo João Goulart}

O presidente João Goulart assumiu o governo em 7 de setembro de 1961. Após a renúncia de Jânio Quadros, em 25 de agosto desse ano, estando Goulart, em missão oficial na China comunista, instaurou-se um clima de grave tensão política no país. Os ministros militares posicionaram-se contrariamente à posse do vice-presidente evocando suas supostas ligações com o comunismo. Diante do impasse gerado, setores políticos e sociais ligados a Goulart iniciaram manifestações em prol de sua posse constitucional, com destaque para a "Campanha da Legalidade", organizada pelo governador gaúcho Leonel de Moura Brizola. Na busca de uma alternativa pacífica, o Congresso Nacional propôs a alteração do regime de governo de forma a conciliar a posse do vice, "exigida pelas ruas", com as restrições dos militares. Dessa forma, viabilizou-se a reforma constitucional que instalou o sistema de governo parlamentarista no Brasil. 
O momento conturbado não se resumia, entretanto, à esfera política. Do ponto de vista econômico, o país assistia a uma crise aguda. Após anos de crescimento acelerado, observado durante governo de Juscelino Kubitschek, a economia nacional entrou em severa crise inflacionária que passava a comprometer os índices de crescimento do Produto. O PIB, que havia crescido, em média, 8,2\% durante os anos de 1956 a 1961, passou a crescer 6,6\% em 1962, 0,6\% e 3,4\% em 1963 e 1964, respectivamente (IBGE, 2003). Por seu turno, a inflação registrada pelo Índice Geral de Preços (IGP), da Fundação Getúlio Vargas, alcançou o patamar de 30,47\% em 1961 e de $47,78 \%$ no ano seguinte (IPEADATA, 2016).

O novo governo, ao mesmo tempo em que padecia diante de sérias dificuldades em estabelecer um equilíbrio de poder entre o presidente e o primeiro-ministro, apresentou as primeiras medidas voltadas a solucionar a crise. O primeiro dos três gabinetes que se sucederam até janeiro de 1963 - liderados por Tancredo Neves, Brochado da Rocha e Hermes Lima, respectivamente - apresentou ao país um plano de combate à inflação de caráter eminentemente ortodoxo, coordenado pelo Ministro da Fazenda Walter Moreira Salles ${ }^{5}$. O plano diagnosticava como causas da inflação a vultosa expansão monetária empreendida pelo governo, a fim de sanar seus déficits de caixa, além do descontrole com que o Banco do Brasil nutria de crédito o setor privado. Assim, a solução proposta passava pela restrição de crédito ao setor privado, bem como pela redução dos gastos públicos e pela necessidade de uma reforma tributária (FONSECA; MONTEIRO, 2005). Na área cambial, propunha-se a manutenção dos intentos de unificação das taxas de câmbio e da política de realismo cambial, iniciada por Jânio Quadros. Como aponta Fonseca (2004), tanto a política cambial, quanto a fiscal e a monetária apresentaram grande dose de austeridade e bases marcadamente liberais, o que se encaixava perfeitamente na busca do presidente de reaproximação junto a credores internacionais, visando sanar o problema das contas externas.

As políticas anti-inflacionárias emergenciais não surtiram o efeito esperado e as políticas mais austeras foram paulatinamente abandonadas devido às dificuldades políticas do gabinete e às eleições parlamentares de 1962, as quais desautorizavam medidas impopulares. As trocas de ministros na Fazenda ${ }^{6}$ demonstraram as dificuldades de se encaminhar uma política de longo alcance naquele cenário político’. À queda do gabinete Neves, seguiu-se o aumento da instabilidade do parlamentaris-

5 Fonseca (2004) sugere que a própria escolha do conservador Moreira Salles para a pasta da Fazenda tenha tido como objetivo principal alcançar maior credibilidade para a política econômica austera de Goulart.

6 Após Moreira Salles (09/09/1961 a 14/09/1962), foram ministros da Fazenda do Governo Goulart, Miguel Calmon (14/09/1962 a 24/01/1963) e já na fase presidencialista, San Thiago Dantas (24/01/1963 a 20/06/1963), Carvalho Pinto (21/06/1963 a 19/12/1963) e Ney Galvão (19/12/1963 a 01/04/1964). Para uma síntese das ações de cada ministro, ver Fonseca (2004).

7 Quanto as dificuldades que o cenário político colocava às políticas econômicas de longo prazo, ver também: Loureiro, 2010 e Mello; Bastos; Araújo, 2006. 
mo, que seria derrotado no plebiscito realizado em janeiro de 1963. A partir de então, e já sob o regime presidencialista, o presidente Goulart pôde, definitivamente, assumir o país com seus poderes constitucionais restabelecidos.

Encerrado o período parlamentarista, o presidente voltou-se para a difícil tarefa de solucionar a crise, que se agravava progressivamente. Com esse intuito, Goulart apresentou o Plano Trienal de Desenvolvimento Econômico e Social (1963-1965). O Plano Trienal, elaborado pelo ministro do Planejamento, Celso Furtado, problematizava a inflação sobre dois pilares temporais. Um aspecto do ciclo inflacionário, dito de curto prazo, foi descrito de forma bastante similar ao diagnóstico convencional de excesso de emissão monetária e de expansão do crédito (VILLELA, 2004). A solução proposta consistia em combater esses focos inflacionários de forma gradual, de modo a não comprometer a retomada do crescimento econômico. Assim, o plano estipulava metas de expansão monetária e do crédito ao setor privado, além do controle dos gastos governamentais que seriam reduzidos a cada ano.

Por outro lado, o plano destacava aspectos de médio e longo prazo - os problemas estruturais - como o foco da inflação e de desajustes sociais da economia. Nesse sentido, foi proposta uma série de reformas de base, dentre as quais, as reformas: agrária, bancária, financeira, tributária, educacional ${ }^{8}$. Acreditava-se, entretanto, que apenas após o restabelecimento das taxas ditas "civilizadas" de inflação, seria possível obter o apoio político necessário à viabilização das reformas mais polêmicas. Assim, a prioridade do plano voltou-se ao combate dos fatores inflacionários ditos de curto prazo (SOLA, 1998).

Nesse contexto é que se enquadram as medidas restritivas dos primeiros meses do governo Goulart em sua fase presidencialista. O governo mostrou-se, nesse período, fortemente decidido a cumprir as metas estabelecidas pelo Plano Trienal. Para tanto, restringiu fortemente o crédito ao setor privado e reduziu os gastos públicos (FONSECA, 2004; FONSECA; MONTEIRO, 2005; MESQUITA, 1992). Quanto ao setor externo, o governo tentava renegociar parte da dívida e obter novos empréstimos, mas também planejava limitar as remessas de lucro das empresas multinacionais como forma de sanear o balanço de pagamentos. $\mathrm{O}$ alcance das metas seria dificultado, entretanto, pelo insucesso das missões enviadas ao exterior para renegociar a dívida externa do país. Como destaca Villela (2004), este fracasso agravou a pouco confortável situação de solvência do país no mercado financeiro internacional uma vez que a dívida externa se encontrava em patamares já elevados devido ao endividamento realizado no período JK.

Muito se questiona a efetividade do Plano Trienal no que tange ao tratamento da questão salarial. Para determinados autores, como Villela (2004) e Abreu (1990), por exemplo, o início de seu fracasso remonta ao reajuste salarial de $60 \%$ concedido

Sobre o Plano Trienal e as Reformas de Base, ver: Furtado (1997, 2011), Goulart (1978), Plano Trienal (1962), Bastos (2011), Loureiro (2010), Macedo (1975), Singer (1974) e Viana (1980). 
ao funcionalismo público em 1963, valor que superava o acordado com o FMI, de 40\%. Para Macedo (1975), o governo Goulart não tratou a questão salarial da forma como deveria, pois, dependia do setor assalariado para se sustentar no poder. Para esse autor, no entanto, uma política inflacionária que não atuasse sobre os níveis salariais seria inconsistente, pois a força de trabalho constitui um fator de produção causador de pressão sobre os custos.

Os reajustes salariais, que se estenderiam para o setor privado com a elevação de 56,25\% no salário-mínimo, reduziram as condições políticas do governo em manter o arrocho do crédito para o empresariado. Após ceder aos trabalhadores, o governo teve que estender o mesmo tratamento aos empresários e afrouxar a política creditícia. Em dezembro de 1963, o Plano Trienal já estava completamente abandonado, o que reforçava a tese da "dificuldade histórica de se montar coalizões anti-inflacionárias - entendidas como uma conjunção de interesses políticos, empresariais e sindicais que se traduzisse em respaldo para medidas de estabilização" (VILLELA, 2004). A partir de então, as contas públicas deterioraram-se completamente e a escalada inflacionária intensificou-se ainda mais.

Uma vez frustrado seu empenho em conter a inflação, por meio de medidas convencionais, o governo voltou-se mais diretamente à defesa das reformas estruturais. Inviabilizada a renegociação da dívida externa, Goulart passou a pressionar os capitais estrangeiros com a aprovação da Lei de Remessa de Lucros. As reformas de base foram apresentadas pelo presidente como a única saída para a manutenção das bandeiras democráticas e de interesse popular. Em 13 de março de 1964, às vésperas do golpe que o apearia do poder, Goulart afirmou, em inflamado discurso realizado na Central do Brasil, no Rio de Janeiro, que:

Governo nenhum, trabalhadores, povo nenhum, poderá enfrentar o monstro inflacionário que devora os salários, que inquieta o povo assalariado, se não foram efetuadas as reformas de estrutura de base exigidas pelo povo e reclamadas pela Nação. Tenho autoridade para lutar pela reforma da atual Constituição, porque seu objetivo único e exclusivo é abrir o caminho para a solução harmônica dos problemas que afligem o nosso povo (GOULART, 1964 apud MARCELINO, 2009, p. 86).

O endurecimento do discurso governamental, tanto em seu viés nacionalista, quanto social-estatista, foi minando gradativamente seu apoio junto aos setores políticos tradicionais. Mesmo a parcela do empresariado, que em alguma medida o havia apoiado no início de seu governo, passou a criticar a guinada à esquerda observada no discurso do presidente. Em Moraes $(2010 ; 2014)$ é possível percebermos que o apoio que Goulart recebe de setores da elite empresarial, no início de seu governo, sempre esteve condicionado ao abandono de certas políticas consideradas radicais. Quando percebem que o governo estava comprometido com um programa de reformas de cunho redistributivo, o empresariado adentra diretamente nas articulações do golpe. 
Nesse cenário, o governo torna-se cada vez mais insustentável politicamente. Afrontando interesses da velha elite agrária, como a defesa da reforma agrária, dos setores empresariais, através da defesa de reformas redistributivas e da cúpula militar, por sua suposta relação com "grupos subversivos", Goulart acabou deposto por um golpe civil-militar, no dia primeiro de abril de 1964, vindo a assumir a Presidência da República o Marechal Humberto de Alencar Castello Branco, um dos líderes do movimento.

Quando vista a partir de uma análise estanque, as políticas econômicas do governo Goulart (tanto em sua fase parlamentarista quanto presidencialista) são definidas por parte da literatura ${ }^{9}$ como erráticas, sem direção nem visão de longo prazo. Quando avaliado em sua inteireza, a partir da forma de entendimento que propomos aqui, o governo Goulart se mostra comprometido com um projeto de mudanças profundas na estrutura social do país, que pode ser resumido no programa das reformas de base (MORAES, 2014). As dificuldades impostas pelo contexto de crise econômica e social impuseram a necessidade de uma série de medidas emergenciais, cuja eficácia dependia da credibilidade em que seu instaurador reunia junto às forças sociais. Nesse sentido, como demonstra Fonseca (2004), pesavam contra Goulart sua dificuldade em dissociar sua imagem de sua base histórica de apoio - setores trabalhistas e sindicais, fator fundamental para dar credibilidade à suas políticas deflacionárias de caráter emergencial. O impasse entre abandonar definitivamente sua base, a fim de se mostrar "forte" 10 e sua disposição em promover reformas estruturais que colocavam em xeque a posição social de elites consolidadas, levaram o governo as idas e vindas materializadas em sua política econômica.

Nesse contexto, Goulart não logrou legitimar sua autoridade frente às classes dominantes em um contexto em que o conflito distributivo se acirrava e o modelo de desenvolvimento baseado na substituição de importações parecia se esgotar. Parece claro, contudo, que tal fato aconteceu não pela fraqueza ou dubiedade de suas ações, mas antes de tudo pelo desacordo entre seu programa e o projeto político das forças econômicas dominantes no país.

\section{0 governo José Sarney}

\subsection{José Sarney: aspectos biográficos}

José Ribamar Ferreira de Araújo Costa nasceu em 1930, no município de Pinheira, interior do Maranhão. De família abastada - seu pai era juiz de direito e

9 Destacam-se, entre outras, as análises de Wells (1977), Serra (1980), Leff (1967), Lessa (1964) e Skidmore (1982).

10 O termo utilizado alude ao fato de estar fortemente comprometido com o combate à inflação, no sentido apresentado em Fonseca (2004), não tendo nenhuma relação com a suposta fraqueza pessoal do presidente sugerida por parte da historiografia. 
desembargador -, formou-se em Direito em São Luís, onde iniciou carreira política ocupando diversos cargos de representação discente, chegando a presidir a Federação Maranhense de Estudantes.

Aos 17 anos de idade iniciou carreira jornalística como repórter policial do semanário O Imparcial, dos Diários Associados. Filiou-se à União Democrática Nacional (UDN) na década de 1950, ocupando a primeira suplência do partido na Câmara Federal após as eleições de 1954. Quatro anos mais tarde, volta ao parlamento como o deputado federal mais votado de seu estado, vindo a assumir a vice-liderança da UDN, no Congresso Nacional, antes de completar 29 anos de idade.

Ainda deputado, participou da criação do grupo da "Bossa Nova", uma dissidência à esquerda no espectro ideológico da UDN, a qual viria a apoiar Jânio Quadros nas eleições de 1960. Quando da ascensão de João Goulart à Presidência da República, porém, Sarney afastou-se do grupo não apenas pelo apoio oferecido ao novo mandatário - o qual ajudaria a derrubar no golpe de 1964 -, mas, principalmente, pela ligação de Goulart com o senador maranhense Vitorino Freire, seu maior adversário político em seu estado natal.

Ainda pelo mesmo partido, elegeu-se governador do Maranhão em 1964, cargo que ocupou até 1970. Nesse mesmo ano, já filiado à Aliança Renovadora Nacional (Arena), partido de sustentação da ditadura militar, elegeu-se senador, mandato que voltou a exercer entre os anos de 1979 e 1985, dessa vez pelo Partido Democrático Social (PDS). E após sua passagem pela Presidência da República, já filiado ao Partido do Movimento Democrático Brasileiro (PMDB), Sarney venceu novamente o pleito para o Senado Federal em 1990, dessa vez pelo estado do Amapá ${ }^{11}$, reelegendo-se em 1998 e em 2006.

A despeito da argumentação baseada na conjuntura local, a filiação tardia ao partido de oposição ao regime discricionário revela a racionalidade subjacente à trajetória política de José Sarney. Ancorado desde sempre no partido alçado ao poder central, Sarney abandonou a legenda que havia presidido até junho de 1984 para ingressar nas fileiras peemedebistas, somente quando já se mostrava avançada a articulação que lhe garantiria o nome na coligação que viria a vencer a eleição no Colégio Eleitoral.

Mais do que a imediata adesão ao governo - afirmação que pode ser corroborada por seu posicionamento político desde que deixou a Presidência da República -, sua biografia política revela seu comprometimento com as causas políticas mais conservadoras, o que sempre lhe garantiu o respaldo do establishment econômico, político e militar em praticamente toda a sua trajetória política.

11 A mudança de domićlio eleitoral deveu-se à influência que Vitorino Freire, seu eterno desafeto, mantinha sobre o PMDB do Maranhão, partido a cujas fileiras viu-se compelido a cerrar para compor a chapa com Tancredo Neves. 


\subsection{A política econômica do governo José Sarney (1985-1990)}

A crise política decorrente do falecimento de Tancredo Neves impôs ao vicepresidente eleito árdua tarefa de articulação política. José Sarney assumiu a Presidência da República com um ministério heterogêneo e plural, cujos titulares não haviam sequer sido por ele nomeados. A frustração dos brasileiros diante da impossibilidade de Tancredo assumir o cargo, somada à identificação do novo presidente com o antigo regime, pelas ruas rechaçado, contribuiu de modo decisivo para a crise de legitimidade que se abateu sobre seu governo.

A esperança subjacente à derrocada do regime autoritário fomentou, no imaginário popular, a expectativa de que o retorno à democracia bastava por si só para extinguir todos os males que acometia a sociedade brasileira, incluindo aí o inimigo público número um daquele momento: a inflação.

Segundo Moura e Lamounier (1986), o fracasso do gradualismo das medidas de combate à inflação adotadas durante o primeiro ano do governo - baseadas em uma pretendida, porém não cumprida austeridade fiscal e monetária - contribuiu para o precoce enfraquecimento da equipe econômica. O choque de oferta agrícola de agosto de 1985, coincidente com o período de entressafra de vários produtos alimentícios, levou a inflação a $14 \%$, ao final daquele mês. Diante desses resultados, somados aos atritos entre o ministro da Fazenda, Francisco Dornelles e seu par do Ministério do Planejamento, João Sayad, tornou-se insustentável a posição daquele, que deixou o cargo no mês de setembro.

A nova equipe econômica que assumiu a pasta da Fazenda diagnosticou a inércia inflacionária como sendo o principal motivo da galopante remarcação de preços, segundo a qual a memória da inflação passada é propagada para os preços, salários e ativos financeiros dos períodos futuros através de mecanismos de indexação. De acordo com Castro (2004), diante das quatro opções de estabilização monetária à época apresentadas, o presidente José Sarney optou pelo "choque heterodoxo" em função de sua prevista repercussão política. Após quase um ano de medidas pontuais que se mostraram incapazes de controlar a inflação, em 28 de fevereiro de 1986, o governo da Nova República lançou o primeiro, e mais controverso, de seus planos de combate à inflação.

As grandes medidas do chamado Plano Cruzado podem ser sintetizadas em quatro pontos: (1) reforma monetária e congelamento; (2) desindexação; (3) alteração nos índices de preços; e (4) política salarial. O primeiro estabelecia o Cruzado como o novo padrão monetário, em substituição ao Cruzeiro. O principal mote do plano, contudo, determinava que os preços de todos os produtos e da taxa de câmbio ficariam congelados a partir do último dia de fevereiro. A figura do "fiscal do presidente", cidadãos que se auto incumbiram de fiscalizar e denunciar estabelecimentos comerciais que remarcassem seus preços, conferiu grande popularidade à figura de José Sarney.

O segundo ponto consistia em substituir as antigas Obrigações Reajustáveis do Tesouro Nacional (ORTN), pelas novas Obrigações do Tesouro Nacional 
(OTN), que continuavam a ser denominadas na antiga moeda, desvalorizadas diariamente, porém, a uma taxa correspondente à inflação apurada entre dezembro de 1985 e fevereiro de 1986. Essa conversão tinha por objetivo minimizar o problema da expectativa de inflação embutida nas obrigações financeiras. A terceira medida propunha o deslocamento do período de apuração do índice de preços oficial (Índice de Preços ao Consumidor Amplo), com o objetivo de eliminar a contaminação do índice pela inflação de fevereiro.

E a última grande proposta do plano referia-se aos salários, que também deveriam permanecer congelados após o reajuste inicial de $8 \%$ para os assalariados em geral e de $16 \%$ para o salário-mínimo. Com o intuito de evitar desgaste com a classe trabalhadora, justamente aquela da qual o governo pretendia se aproximar, foi criado o "gatilho salarial", instrumento que garantiria a correção imediata dos salários sempre que a inflação acumulasse $20 \%$.

O retumbante sucesso inicial do Plano Cruzado sugeria o êxito dos objetivos inicialmente traçados: o econômico (eliminar a inflação livrando o país da recessão) e o político (conferir legitimidade ao governo). A taxa de inflação praticamente zerou em março e abril, permanecendo abaixo dos $2 \%$ até outubro. Já a taxa de desemprego caiu para 3,8\% antes ainda do mês de maio. Os reveses fiscais e de balanço de pagamentos, contudo, não tardaram a surgir. A redução da receita de senhoriagem e o congelamento de algumas tarifas públicas impactaram fortemente as contas públicas. E o aumento descontrolado da demanda, que já se mostrava anteriormente aquecida, desencadeou graves problemas de desabastecimento, contra os quais se recorreu às importações, o que, por sua vez, deteriorou ainda mais os saldos da balança comercial.

A equipe econômica logo detectou os perigos de um superaquecimento da demanda. A inviabilidade política de um descongelamento e a cisão interna entre os técnicos do próprio Ministério da Fazenda impossibilitaram, contudo, medidas de maior alcance. De modo que, em 23 de julho do mesmo ano, lançou-se o dito Cruzadinho, um simples pacote fiscal com o objetivo de desaquecer o consumo e financiar um plano de infraestrutura e de metas sociais. O reajuste dos preços proposto no pacote, contudo, foi expurgado do índice oficial de inflação. $O$ fracasso da medida foi geral, não atendendo nem às necessidades de frear a demanda, tampouco às de gerar recursos para as obras de infraestrutura prometidas pelo governo. Nesse sentido é que Modiano (1990) analisa o agravamento da conjuntura ao afirmar que "o segundo período, que vai de julho a outubro de 1986, pode ser identificado pela total imobilidade do governo ante o agravamento da escassez de produtos e à deterioração das contas externas." (Ibid., p. 360, grifos do autor).

A deterioração dos fundamentos macroeconômicos ao longo do segundo semestre de 1986 - com destaque para constantes os déficits do balanço de pagamento em transações correntes -, fomentou o lançamento, em novembro desse ano, do chamado Cruzado II, mais um novo pacote fiscal que tinha por objetivo aumentar a arrecadação em $4 \%$ do PIB. A remarcação dos preços de determinados produtos 
aos consumidores finais e de algumas tarifas públicas serviram, na prática, como aval para que o congelamento fosse finalmente abolido. Em janeiro de 1987, o gatilho salarial foi disparado, o que aumentou ainda mais a descrença dos agentes econômicos no governo, levando à extinção oficial do plano no mês subsequente. Em abril, após as repercussões negativas da moratória da dívida externa, o presidente Sarney demitiu o ministro da Fazenda e sua equipe.

De acordo com os próprios formuladores do Plano Cruzado, erros de concepção e de condução foram decisivos para o seu fracasso, a saber: (1) o diagnóstico de que a inflação era puramente inercial estava equivocado; (2) a inconveniência técnica dos abonos salariais concedidos antes do congelamento; (3) a condução das políticas monetária e fiscal foi menos austera do que o necessário ${ }^{12}$; (4) o período do congelamento de preços foi demasiadamente longo, tendo sido os valores mantidos em seus níveis correntes, distorcendo ainda mais os preços relativos; (6) o gatilho salarial indexou ainda mais a economia; (7) a manutenção do câmbio fixo deteriorou as contas externas e (8) a defasagem dos preços públicos piorou a situação fiscal do governo.

Após a saída dos burocratas responsáveis pelo Cruzado, assumiu o Ministério da Fazenda, em abril de 1987, o economista Luiz Carlos Bresser-Pereira, permanecendo no cargo por um período inferior a oito meses. O novo ministro lançou, em 12 de junho, a segunda tentativa de estancar o avanço dos preços. O chamado Plano Bresser foi concebido como um pacote híbrido, reunindo um conjunto de medidas heterodoxas e ortodoxas. O objetivo da nova equipe econômica era estabilizar a economia sem incorrer nos equívocos do Cruzado. Ao contrário desse, porém, "o Plano Bresser não tinha como meta a inflação zero, nem tencionava a eliminar a indexação da economia." (MODIANO, 1990, p. 366).

Pelo lado ortodoxo, o governo propunha políticas fiscal e monetária austeras como instrumentos a serem utilizados ativamente no combate à inflação. Já no grupo de medidas heterodoxas, foi anunciado um novo congelamento de preços e salários com duração pré-anunciada de três meses. Os salários ficariam indexados a uma nova base, a Unidade de Referência de Preços (URP), formada a partir da inflação apurada nos três meses antecedentes (CASTRO, 2004, p. 129).

A despeito do sucesso inicial no tocante ao controle da inflação, a expectativa de que o congelamento perdurasse por tempo indeterminado incitou a remarcação preventiva de preços em diversos setores, fazendo com que a inflação subisse dos 6,4\% em agosto para 14,1\% em dezembro. O ajuste fiscal e a reforma tributária progressista propostos também não saíram do papel, contribuindo ainda mais para

12 Modiano (1990) frisa a posição acessória destes instrumentos em “o Plano Cruzado não estabeleceu regras ou metas para as políticas monetária e fiscal para complementar o programa de estabilização (...), sendo relegada ao discernimento dos responsáveis pela política econômica.” (p. 359) e em "quando se verificou aumento da receita, este foi mais do que neutralizado pelo aumento de gastos, fruto da necessidade de se sustentar o congelamento de preços e, portanto, contribuir para a vitória do PMDB nas eleições de novembro.” (p. 362). 
a insatisfação do ministro. A falta de apoio político por parte do presidente da República forçou Bresser-Pereira a pedir demissão ainda em dezembro do mesmo ano.

Em janeiro de 1988, assumiu o último ministro da Fazenda do governo Sarney, o funcionário do Banco do Brasil, Maílson da Nóbrega. Durante os mais de dois anos em que permaneceu no cargo, o ministério promoveu uma guinada efetiva, conduzindo a economia brasileira com medidas ortodoxas e liberalizantes. De início, o novo ministro propôs um programa gradualista, baseado na contenção do déficit público e dos valores nominais dos empréstimos ao setor público. Ainda que o anúncio reiterado de que não se adotaria um novo congelamento de preços tenha contribuído para a contenção das taxas de inflação, ao longo de todo o primeiro semestre do ano, a política monetária, contudo, não logrou ser contracionista o suficiente devido ao efeito de esterilização causado pelos mega-superávits da balança comercial. O aumento de determinados preços públicos e uma quebra agrícola impulsionaram a inflação oficial para $24 \%$ em julho de 1988 , determinando o fracasso dessa estratégia parcimoniosa (LOPES, 1986).

Diante de mais esse revés, em 14 de janeiro de 1989, o governo lançou mão de sua terceira tentativa de contenção dos preços. O Plano Verão, um programa concebido com elementos ortodoxos (redução de despesas de custeio, privatizações, limitações à emissão de títulos públicos, juros elevados e medidas de restrição de crédito) e heterodoxos (novo congelamento de preços e salários por tempo indeterminado e a extinção de mecanismos de indexação), também introduziu um novo padrão monetário, o Cruzado Novo. Além disso, o dólar foi fixado, por tempo indeterminado, em uma paridade unitária em relação à nova moeda, medida a qual, segundo Modiano (1990, p. 376), "teria um efeito psicológico positivo, na medida em que fosse percebida como um indicador da disposição efetiva do governo em combater a inflação doméstica.”

O plano, entretanto, incorria em riscos. Consoante Bier (1987), o descrédito da população, após sucessivas tentativas frustradas de estabilização e a marcha rumo à hiperinflação caso as medidas viessem a falhar, uma vez que haviam sido eliminados os indexadores da URP e OTN, exerciam pressão tal sobre a equipe econômica a ponto de o Plano Verão ter sido considerado a resposta oficial ao "ultimato" lançado contra o governo.

Devido às eleições presidenciais de 1989, o ajuste fiscal não ocorreu na prática. O temor de descontrole dos preços após o congelamento fez com que os altos juros praticados não desestimulassem o consumo. Devido à extinção dos indexadores, cada agente passou a utilizar o índice que melhor lhe conviesse, o que resultou em nova escalada dos preços ao final do ano devido à diminuição cada vez maior dos períodos de reajuste. Além disso, as defasagens dos preços públicos, indefinições quanto à reindexação, o aumento do déficit público e a forte expansão monetária contribuíram para a explosão inflacionária em dezembro, quando o INPC atingiu a taxa de 51,5\%. A despeito de não ter logrado derrotar a escalada dos preços, o Plano Verão teve o êxito de interromper uma escalada hiperinflacionária que se avizinhava. 
Ao final do mandato do presidente José Sarney, tornou-se claro que a repetição de programas similares era ineficaz, uma vez que a sociedade aprendera a burlar os congelamentos. Para Modiano (1990), os três planos não representaram mais do que um represamento temporário da inflação, uma vez que não a eliminaram, não resolveram o conflito distributivo e não reduziram a transferência de recursos reais ao exterior. As tentativas de estabilização da economia durante o período da Nova República, contudo, não podem ser arroladas junto aos fracassos da história econômica brasileira. A despeito de não terem atingido seu objetivo último, lições importantes foram aprendidas pelos mesmos burocratas que, em 1994, lograram derrotar a inflação com o lançamento do Plano Real.

Diante da restituição de fatos acima realizada, faz-se oportuno destacar a nítida guinada patrocinada pelo governo Sarney rumo às políticas econômicas de cunho ortodoxo. Excetuando-se o primeiro ano de meias-estratégias, período em que se levou a cabo um programa gradual de medidas de austeridade, é possível dividir esquematicamente o período do governo Sarney em três diferentes fases: o choque heterodoxo de fevereiro de 1986, o hibridismo do Plano Bresser ao longo de 1987 e a ortodoxia iniciada a partir do lançamento do Plano Verão, em janeiro de 1989.

A sequência de fatos históricos que levaram o então senador José Sarney à Presidência da República responde por parcela significativa da crise de legitimidade que açoitou os cinco anos de seu mandato. As inúmeras aspirações sociais, reprimidas em duas décadas de regime autoritário, terminaram por estreitar ainda mais o já tênue equilíbrio de forças sobre o qual o presidente governou o país. Desamparado pelas lideranças políticas, Sarney procurou, nas ruas, o apoio imprescindível a um governante carente de credibilidade (SALOMÃO, 2010).

A necessidade premente de se aproximar da população foi muito bem instrumentalizada pelo primeiro grande choque, cujo forte apelo popular elevou a níveis recordes a aprovação do presidente da República. Após a sucumbência do Cruzado, José Sarney chancelou uma tentativa híbrida, a despeito dos importantes elementos heterodoxos contidos no Plano Bresser. A ausência de resultados positivos desestabilizou politicamente seu terceiro ministro da Fazenda, levando-o a renunciar sem completar um ano no cargo. A hiperinflação que se anunciava, decorrente do fracasso de dois planos não convencionais de combate à inflação, impeliu o presidente, restando apenas dois anos para o fim de seu mandato, a adotar um plano com claros elementos ortodoxos, o qual previa o início do processo de desestatização e a incipiente abertura da economia brasileira.

\section{Considerações finais}

Conforme a máxima do filósofo George Santayana, aqueles que não lembram o passado estarão condenados a repeti-lo. Se extrapolado para eventos econômicos, $\mathrm{o}$ adágio do pensador espanhol aufere contornos ainda mais convincentes. A breve história política brasileira da segunda metade do século XX presta-se como um de seus mais eloquentes testemunhos. 
Conforme se procurou demonstrar, os presidentes João Goulart e José Sarney reagiram de modo distinto no enfrentamento das crises de legitimidade que se abateram sobre seus mandatos quando de suas respectivas posses. Se Jango partiu de ações conservadoras para radicalizar suas políticas apenas no final de seu mandato, Sarney patrocinou um plano de estabilização monetária de clara concepção heterodoxa antes de completar um ano de governo. Somente após o seu fracasso foi que o vice de Tancredo se rendeu paulatinamente às políticas de cunho ortodoxo.

Por quais motivos, então, dois vice-presidentes com dificuldades em se legitimar, traçariam estratégias tão distintas? A hipótese defendida nesse trabalho reside nas diferentes trajetórias políticas de ambos os governantes e nos grupos sociais com os quais sua história os identificava. Ligado ao trabalhismo varguista e às causas progressistas, Jango viu-se compelido a buscar o apoio do empresariado e do establishment econômico, a fim de comprovar o seu compromisso com temas caros aos meios conservadores, como a garantia da propriedade privada e a posse da terra, e em um caráter mais emergencial o combate à inflação. Uma vez convencido de que essa estratégia pouco exitosa não lhe garantiria o apoio dos grandes industriais, o presidente chancelou a guinada rumo às políticas condizentes com sua biografia política.

Já no caso de Sarney, a situação se apresentava inversa. Historicamente ligado aos interesses políticos e economicamente conservadores, se não contava com o apoio da mídia e dos políticos do Sudeste, o ex-presidente nacional do PDS tampouco angariava a antipatia do mercado e da elite econômica do país. De posse desse capital político - do qual João Goulart jamais gozou -, Sarney pôde experimentar políticas de ampla repercussão popular para tentar granjear nas ruas a falta de legitimidade negada pelas urnas. Conquanto tenha fracassado, o Plano Cruzado, por exemplo, não contrariou os interesses estabelecidos nem tampouco gerou uma crise institucional. Seguro de que o histrionismo econômico não lhe conferiria o apoio de que carecia, o presidente sucumbiu, então, aos apelos da ortodoxia com a qual terminou seu mandato de forma melancólica.

Trata-se, pois, de dois exemplos lapidares em demonstrar que a política econômica não deriva sobre o nada, sendo fruto unicamente da racionalidade - ou falta dela - dos policymakers ligados ao controle do Estado. Conforme se procurou demonstrar, parece-nos aceitável a percepção de uma realidade influenciada por diversos poderes que se concretiza nessa ou naquela medida. $\mathrm{O}$ que muitas vezes se parece com políticas erráticas de um presidente fraco, poderia ser mais bem explicado como uma luta constante de poderes que tende para os diferentes lados a depender da correlação de forças.

A busca de legitimidade - especialmente diante dos grupos sociais de maior poder, como foi o caso de Goulart - parece ter marcado de forma direta sua política econômica. Por outro lado, a "confiança" desses mesmos setores dominantes permitiu a Sarney que intentasse alcançar, nas ruas, a legitimidade social de que carecia seu mandato. Nenhum dos dois foi plenamente exitoso, o que demonstra a grande dificuldade que apresenta uma sociedade, cingida por grandes desajustes estruturais, em construir pactos sociais em momentos de crise. 
No aforismo consagrado por Marx, a história tenderia a se repetir. Na primeira vez, como tragédia; na segunda, como farsa. Premonitória, a história brasileira demonstra que tentativas de desestabilização política de um presidente constitucionalmente eleito acabam por resultar em crises institucionais das quais nenhuma medida econômica - por mais bem embasada do ponto de vista teórico ou pelo maior respaldo popular por ela angariada - poderá resgatá-lo.

\section{Referências}

ABREU, Marcelo de P. Inflação, estagnação e ruptura: 1961-1964. In: ABREU, Marcelo de P. A ordem do progresso: cem anos de política econômica republicana. Rio de Janeiro: Campus, 1990.

BANDEIRA, Moniz. O governo João Goulart: as lutas sociais no Brasil. Rio de Janeiro: Civilização Brasileira, 1978.

BASTOS, Pedro Paulo Zahluth. O Plano Trienal e sua economia política. In: FURTADO, Celso. O Plano Trienal e O Ministério do Planejamento. Rio de Janeiro: Centro Celso Furtado / Ed. Contraponto, 2011.

BASTOS, Pedro Paulo Zahluth. Ascensão e crise do projeto nacional-desenvolvimentista de Getúlio Vargas. In: BASTOS, Pedro Paulo Zahluth; FONSECA, Pedro Cezar Dutra (orgs.) A Era Vargas: desenvolvimentismo, economia e sociedade. São Paulo: Editora Unesp, 2012.

BIER, Amaury G. O heterodoxo e o pós-moderno: o Cruzado em conflito. Rio de Janeiro: Paz e Terra, 1987.

CASTRO, Lavínia B. de. Esperança, frustração e aprendizado: a história da Nova República. In: GIAMBIAGI, Fabio et al. (Org.). Economia brasileira contemporânea. Rio de Janeiro: Campus-Elsevier, 2004.

FERREIRA, Jorge. João Goulart: Uma biografia. Rio de Janeiro: Civilização Brasileira, 2011.

FONSECA, Pedro Cezar D. Vargas: o capitalismo em construção. São Paulo: Brasiliense, 1989.

FONSECA, Pedro Cezar D. Varga. Legitimidade e credibilidade: impasses da política econômica do governo Goulart. Revista Estudos Econômicos IPE-USP, São Paulo, SP, v. 34, n. 3, p. 587-622, 2004. crossrefhttps://doi.org/10.1590/S010141612004000300007 
FONSECA, Pedro Cezar D.; MONTEIRO, Sergio M. M. Credibilidade e populismo: a política econômica dos governos Vargas e Goulart. Revista Brasileira de Economia. Rio de Janeiro, v. 59, n. 2, p. 215-243, abr./jun. 2005.

FURTADO, Celso. A Fantasia Desfeita. In: FURTADO, Celso. Obra Autobiográfica de Celso Furtado. Rio de Janeiro: Paz e Terra, 1997.

FURTADO, Celso. O Plano Trienal e O Ministério do Planejamento. Rio de Janeiro: Centro Celso Furtado / Ed. Contraponto, 2011.

GASPARI, Elio. A ditadura encurralada. São Paulo: Companhia das letras, 2004.

GOULART, João. João Goulart 1962-1964. In: BRASIL. Presidente. Mensagens Presidenciais 1947-1964. Brasília: Centro de Documentação e Informação/Coordenação de Publicações, 1978. p. 361-435.

IBGE. Estatísticas do Século XX. Rio de Janeiro: IBGE, Centro de Documentação e Disseminação de Informações, 2003.

IPEADATA. Inflação IGP-DI Anual de 1945 até 2015. Disponível em http://www. ipeadata.gov.br. Acesso em 11 abr. 2016.

LEFF, Nathaniel. Politica econômica e desenvolvimento no Brasil, 1947-1964. São Paulo: Perspectiva, 1967.

LESSA, Carlos. Quinze anos de política econômica. São Paulo: Brasiliense, 1964.

LOPES, Francisco L. O choque heterodoxo: combate à inflação e reforma monetária. Rio de Janeiro: Campus, 1986.

LOUREIRO, Felipe. Uma difícil conciliação: empresários e trabalhadores no contexto do Plano Trienal. História Econômica E História de Empresas. $N^{\circ}$ XIII. Ano 2. pp. 109-143, 2010.

MACEDO, Roberto B. M. Plano Trienal de Desenvolvimento Econômico e Social (1963-1965). In: LAFER, Betty M. Planejamento no Brasil. São Paulo: Perspectiva, 1975.

MARCELINO, Wanielle Brito. Discursos selecionados do presidente João Goulart. Brasília: FUNAG, 2009.

MELO, Hildete Pereira de; BASTOS, Carlos Pinkusfeld Monteiro; ARAÚJO, Victor Leonardo. A política macroeconômica e o reformismo social: impasses de um 
governo sitiado. In: FERREIRA, Marieta de Moraes. João Goulart: entre a memória e a história. Rio de Janeiro: Editora FGV, 2006.

MESQUITA, Mario. 1961-1964: a política econômica sob Quadros e Goulart. 1992. Dissertação de Mestrado, Departamento de Economia, PUC-RJ, 1992.

MODIANO, Eduardo M. Da inflação ao Cruzado: a política econômica no primeiro ano da Nova Republica. Rio de Janeiro: Campus, 1986.

MODIANO, Eduardo M. A ópera dos três Cruzados. In: ABREU, Marcelo de P. (Org.). A ordem do progresso. Rio de Janeiro: Campus, 1990.

MORAES, Rafael. Os governos João Goulart e Castello Branco vistos pela FIESP: uma análise da relação entre o estado e o empresariado industrial. Dissertação de Mestrado, Programa de Pós-Graduação em Economia, UFRGS, 2010.

MORAES, Rafael. O governo João Goulart e o empresariado industrial: tensões e rupturas na última valsa do social-desenvolvimentismo no Brasil (1961-1964). Anuario CEEED, $\mathrm{n}^{\circ}$ 6, ano 6, pp. 83-114, 2014.

MOURA, Alkimar R.; LAMOUNIER, Bolívar. Política econômica e abertura política no Brasil - 1973/1983. Textos IDESP, no 4. São Paulo: IDESP, 1986.

PLANO Trienal. Revista Brasileira de Economia, Rio de Janeiro, v. 16, n.4, dez. 1962. Edição Especial.

SALOMÃO, Ivan C. Arroubos econômicos, legitimação política: uma análise da moratória da dívida externa de 1987. Dissertação de Mestrado, Programa de Pós-Graduação em Economia, UFRGS, 2010.

SERRA, José. Ciclo e mudanças estruturais na economia brasileira do após guerra. In: BELLUZZO, L. G; COUTINHO, R. (Orgs.). Desenvolvimento capitalista no Brasil. Campinas: Instituto de Economia-Unicamp, 1980.

SINGER, Paul. Análise Crítica do Plano Trienal. In: SINGER, Paul. Desenvolvimento e Crise, 3. ed. São Paulo: Difel, 1974. p. 97-126.

SOLA, Lourdes (org.). O Estado da Transição: política e economia na Nova República. São Paulo: Vértice, 1988.

SOLNIK, Alex. Os pais do Cruzado contam por que não deu certo. São Paulo: L\&PM, 1987. 
SKIDMORE, Thomas. Brasil: de Getúlio a Castello. Rio de Janeiro: Paz e Terra, 1982.

VIANA, Cibilis da Rocha. Reformas de Base e a Política Nacionalista de Desenvolvimento - de Getúlio a Jango. Rio de Janeiro: Civilização Brasileira, 1980.

VILLELA, André. Dos “Anos Dourados” de JK à crise não resolvida (1956-1963). In: GIAMBIAGI, Fabio et al. (Org.). Economia brasileira contemporânea. Rio de Janeiro: Campus-Elsevier, 2004.

WEBER, Max. Economia e sociedade. Fundamentos da sociologia compreensiva. Vol. 1. Brasília: Ed. Universidade de Brasília, 2000.

WELLS, John Richard. Growth and Fluctuations in the Brazilian Manufacturing Sector during the 1960s and Early 1970s. Tese de doutoramento: Universidade de Cambridge, 1977.

Recebido em 13.04.16 Aprovado em 19.08.16 
